\title{
Antibiosis resistance against larval cabbage root fly, Delia radicum, in wild Brassica-species
}

\author{
Wang Shuhang • Roeland E. Voorrips • \\ Greet Steenhuis-Broers • Ben Vosman • \\ Joop J. A. van Loon
}

Received: 15 January 2016/Accepted: 17 May 2016/Published online: 1 June 2016

(C) The Author(s) 2016. This article is published with open access at Springerlink.com

\begin{abstract}
Cabbage root flies (Delia radicum) are a major threat to cabbage production in Western Europe and North America. Host plant resistance is the most promising option in controlling cabbage root fly damage. In a no-choice field test, we evaluated 94 accessions belonging to 16 Brassica-species for antibiosis resistance against the larvae. Thirteen accessions were selected as putatively resistant, which were subsequently re-tested in the greenhouse. The proportion of eclosed flies was introduced as the main parameter to assess antibiosis in the greenhouse, together with other insect and plant parameters. High levels of antibiosis resistance were identified in $B$. fruticulosa PI663081 and B. spinescens BRA2994, with significantly lower proportions of eclosed flies ( $1 \%$ of the number of eggs used for infestation) compared to other accessions. Both species are difficult to cross with $B$. oleracea. Plants with a high level of antibiosis and medium to high tolerance were
\end{abstract}

Electronic supplementary material The online version of this article (doi:10.1007/s10681-016-1724-0) contains supplementary material, which is available to authorized users.

W. Shuhang · J. J. A. van Loon ( $₫)$

Laboratory of Entomology, Wageningen University,

P.O. Box 16, 6700 AA Wageningen, The Netherlands

e-mail: joop.vanloon@wur.nl

R. E. Voorrips · G. Steenhuis-Broers ·

B. Vosman · J. J. A. van Loon

Wageningen UR Plant Breeding, Wageningen,

The Netherlands found in several accessions of other Brassica species (B. villosa BRA2922, B. montana BRA2950, B. hilarionis HRIGU12483, B. macrocarpa BRA2944) which are more amenable for crossing with $B$. oleracea. Selection of the most resistant plants belonging to these accessions may yield promising candidates for breeding cabbages resistant to Delia radicum.

Keywords Cabbage root maggot $\cdot$ Host plant resistance $\cdot$ Eclosion - Brassica oleracea - Insect resistance

\section{Introduction}

Cabbage root fly [Delia radicum (Linnaeus 1758) (Diptera: Anthomyiidae)] is one of the most damaging pests in cabbage (Brassica oleracea $L$.) production in Western Europe and North America (Dosdall et al. 1994; Finch and Coaker 1969). Female flies lay eggs close to the stem base on the soil surface. Larvae of the root flies feed on the root tissue of the cabbage plants followed by fungal invasion of the wound, which may result in growth retardation or even plant mortality. In temperate zones root fly damage is severe in spring and early summer (Griffiths 1986) when overwintered adult flies oviposit on young plants, whereas in warmer climatic zones the root fly persists the whole year (Joseph and Martinez 2014). In Western Europe 
and North America, economic losses due to root fly damage have been estimated to amount up to $\$ 100$ million in some years. Furthermore, cabbage root fly infestations cause substantial yield losses in various other Brassica crops including broccoli, cauliflower, turnip, and rutabaga (Finch and Ackley 1977).

The threat by cabbage root fly has recently become acute due to the restrictions in the use of chemical insecticides worldwide. Over the last 20 years, farmers extensively applied chemical insecticides to control cabbage root flies. Apart from the fact that the root fly has already developed resistance to many insecticides (Myrand et al. 2015), most of these chemicals are hazardous to the environment and have been banned or are likely to be banned in the near future. For example, the European Union has banned the major insecticide Lindane, a chlorinated hydrocarbon [European Union Regulatory Decision 79/117/EEC (1981) and 304/2003 (00/801)]; in the U.S., increasing restrictions on the use of organophosphate insecticides also led to increased yield loss in cabbage crops due to cabbage root fly (Joseph and Martinez 2014). Furthermore, the lack of effective biological or cultural/physical control methods is an issue. Biological control measures include the use of predators e.g. Aleochara bipustulata (Linnaeus 1761) (Coleoptera: Staphylinidae) (Coaker and Williams 1963), parasitoids Trybliographa rapae (Westwood 1835) (Hymenoptera: Figitidae) and Aleochara bilineata (Gyllenhal 1810) (Coleoptera: Staphylinidae), entomopathogenic nematodes Steinernema carpocapsae (Weiser) and S. feltiae (Filipjev) (Rhabditida: Steinernematidae) (Georgis et al. 2006) and entomopathogenic fungi e.g. Metarhizium anisopliae (Sorokin 1883) and Beauveria bassiana (Vuillemin 1912) (Hypocreales: Clavicipitaceae) (Bruck et al. 2005; Chandler and Davidson 2005; Vänninen et al. 1999). However, these methods are either costly or labour intensive, or not effective enough to offer sufficient control of D. radicum (Finch 1993; Vänninen et al. 1999; Myrand et al. 2015). Cultural methods such as cover crops are only economical for organic Brassica crops sold at higher prices (Finch 1993). Adapting sowing times could avoid root fly infection, but would lead to large reductions in yield (Finch 1993). Other cultural practices such as intercropping (Hummel et al. 2010) and using exclusion fences (Bomford et al. 2000) can reduce crop damage (Dosdall et al. 2000) to a certain extent, yet not sufficiently. Kergunteuil et al. (2015) proposed a push-pull system by intercropping of repellent and trap plants to limit $D$. radicum density, though further investigation on its effectiveness is pending. To cope with the increasing threat by root flies, alternative control methods are urgently needed.

Host plant resistance is the most promising option in controlling insect pests in crops (Broekgaarden et al. 2011; Schoonhoven et al. 2005). Examples can be found in many vegetable crops, e.g. host plant resistance in Lactuca spp. to the lettuce aphid, Nasanovia ribisnigri (Mosely 1841) (Homoptera: Aphididae) was found economically and environmentally effective in controlling this pest (McCreight 2008). The resistance conferred by the $N r$-locus resulted in reduced performance and feeding rate of aphids (Eenink and Dieleman 1983; ten Broeke et al. 2013). To find host plant resistance, natural variation among wild relatives of crop species can provide good sources (Broekgaarden et al. 2011). Tomato resistance to the whitefly species Bemisia tabaci (Gennadius, 1889) (Hemiptera: Aleyrodidae) and Trialeurodes vaporariorum (Westwood 1856) (Hemiptera: Aleyrodidae) was found in several wild species and QTLs were identified for reduced oviposition rate (Lucatti et al. 2010, 2013, 2014) and whitefly adult survival (Muigai et al. 2002, 2003; Firdaus et al. 2013; Lucatti et al. 2013). Also, sources of resistance against the Colorado potato beetle Leptinotarsa decemlineata (Say, 1824) (Coleoptera: Chrysomelidae) were found among wild relatives of potato (Maharijaya and Vosman 2015). Important resistance to biotic stresses was found among wild B. oleracea species (Kole 2011). Regarding insect resistance, Ellis et al. (2000) found germplasm that was resistant to the cabbage aphid Brevicoryne brassicae (Linnaeus 1758) (Hemiptera: Aphididae) in B. villosa and B. incana. Resistance to flea beetles Phyllotreta cruciferae (Goeze 1777) was found in B. incana (Bodnaryk 1992). In addition, several authors (Bodnaryk 1992; Ramsey and Ellis 1996; Pelgrom et al. 2015) have reported on accessions resistant to cabbage whitefly Aleyrodes proletella (Linnaeus 1758) (Hemiptera: Aphididae) among $B$. oleracea var. capitata landraces and in the wild species $B$. villosa, $B$. incana, $B$. montana, $B$. cretica, B. spinosa, B. insularis and B. macrocarpa.

Three resistance mechanisms have been described in the literature on Delia-Brassica interactions, antixenosis, antibiosis and tolerance (Painter 1951). Antixenosis, also called non-preference, is based on 
morphological and/or chemical characteristics that make a plant unattractive to insects for feeding or oviposition (Painter 1941; Kogan and Ortman 1978; Acquaah 2012). Antibiosis causes adverse effects on insect life history when the insect uses a resistant hostplant variety for food (Painter 1941). Typically, antibiosis increases mortality or reduces the growth and development of insects (Acquaah 2012). This mechanism manifests itself after a host has been attacked and thus affects only the $D$. radicum larvae that feed on the root system. Tolerance refers to the ability of plants to grow and reproduce normally or to repair injury to a marked degree in spite of supporting a population approximately equal to that damaging a susceptible host (Painter 1951). Different from the other two mechanisms, tolerance is independent of the herbivore response, but is an adaptive mechanism for survival of a plant under herbivore pressure (Kogan and Ortman 1978).

A number of studies on the oviposition preferences (antixenosis) of adult Delia radicum demonstrated large variation among different crop species and genotypes (Baur et al. 1996; Ellis and Hardman 1975; Ellis et al. 1976, 1979; Kergunteuil et al. 2015). However, this resistance mechanism has not been shown strong enough for preventing economic damage in B. oleracea monocultures. Antibiosis resistance to larvae and/or pupae of Delia spp. may be the most effective among the three mechanisms mentioned above, and has been reported in wild Brassica or other brassicaceous species in several studies. Ellis et al. (1999) screened several Brassica species and found that high levels of antibiosis were present in $B$. fruticulosa, B. incana, B. villosa and B. spinescens, showing a reduced percentage pupation and high plant survival. They also found that B. macrocarpa and $B$. villosa were moderately resistant and all the tested $B$. oleracea accessions and cultivars were highly susceptible. In their study all accessions tested were accepted for oviposition, indicating that antixenosis is not always associated with antibiosis resistance (Finch and Ackley 1977; Wiklund 1975). Jyoti et al. (2001) found antibiosis resistance in Sinapis alba, reducing weight and survival of larvae, pupae and adults of $D$. radicum. Resistance to D. radicum found in Sinapis alba has been successfully transferred into canola (Brassica napus L.) as well as B. rapa L. and two quantitative trait loci (QTLs) associated with resistance were identified (Ekuere et al. 2005). Malchev et al. (2010) introduced the resistance from canola into rutabaga (B. napus. var. napobrassica), using marker assisted selection (MAS). In a comparative study of four $B$. fruticulosa and two B. oleracea accessions, Felkl et al. (2005) found evidence for antibiosis, as few individuals reared on resistant B. fruticulosa accessions developed into pupae that had reduced pupal weight, adult dry weight, and an extended pupal eclosion time. It should be noted that the most susceptible $B$. fruticulosa accession was comparable to the two $B$. oleracea accessions for various damage and insect growth parameters, indicating that within $B$. fruticulosa considerable variation in level of antibiosis resistance against $D$. radicum exists.

In this study we aimed to identify and quantify antibiosis-based resistance to D. radicum larvae by screening 94 accessions belonging to 16 species in the genus Brassica. For this purpose, no-choice resistance tests were performed in a two-step approach: a field test followed by a greenhouse test. The field test provided an efficient first screening of many accessions, and allowed us to target accessions that possibly possessed resistance. Accessions selected from the field were then subjected to a greenhouse test that allowed a more detailed evaluation of the insect and plant traits important for resistance.

\section{Materials and methods}

Plant materials and insect rearing

Seeds of Brassica accessions were obtained from different gene banks (Online Resource 1). Plant growing conditions are specified for each experiment below. The colony of $D$. radicum originated from a field at St. Méloir des Ondes (Brittany, France) in 1994 (Pierre et al. 2013), and has been kept as laboratory colony since. The rearing was kept in a climatecontrolled cabinet at $22{ }^{\circ} \mathrm{C}$, RH $60 \%$ and a photoperiod of $16 \mathrm{~h}$ light $/ 8 \mathrm{~h}$ darkness. The method of rearing was based on the description of Neveu and Nenon (1996). The larvae were fed on turnips (Brassica rapa) and rutabaga (Brassica napus) until pupation. Eclosed adult root flies were kept in gauze cages and were fed on a mixture of sugar, milk powder and yeast in ratio 1:1:1 (Kergunteuil et al. 2015). Tap water was offered in a Petri dish with moist filter paper on top of wet cotton wool. Oviposition was stimulated by placing a 
slice of turnip in the cage. The turnip slice was put on top of a moist filter paper in a Petri dish, to prevent desiccation. Eggs were collected around the slice of turnip after approximately $3 \mathrm{~h}$. The eggs were then placed on intact turnips or rutabaga prior to hatching of larvae. At $22{ }^{\circ} \mathrm{C}$, it usually took about 4 days for the larvae to hatch from the eggs.

\section{Field experiment}

Resistance screening was carried out in a field (clay soil) near Wageningen, The Netherlands (N51.96, E5.65). Ninety-four accessions of various Brassica species (Table 1) were sown in germination trays in May 2012. After germination, plants were transplanted into to $\varnothing 14 \mathrm{~cm}$ pots with potting compost (Online Resource 2). Plants were reared in a greenhouse compartment before transplanting into the field. When most of the plants from one accession had 5-6 true leaves, five of each accession were infested with 20 eggs of D. radicum per plant (Felkl et al. 2005). Freshly laid or one-day old eggs were used for infestation and placed on the moist surface of the potting compost, close to the stem. One week after infestation the plants were transplanted into the field. Plants were randomized in two blocks and planted at $50 \mathrm{~cm}$ distance from each other within a row and 50 or $75 \mathrm{~cm}$ between rows. Wilting of leaves, collapse (all leaves wilted and main stem falling over, plants are still green) or death (plant had no green leaves left) were observed twice a week after plants had been transplanted into the field. Plant vigour was scored per accession three weeks after transplanting, using a semi-quantitative scale from 1 to 4 , where $1=$ all the tested plants are very small and poorly developed, all individuals are wilted or collapsed; $2=$ all the tested plants are small, with many individuals wilting, 3 = plants are generally well developed, with two or three of the five plants wilting or small in size; $4=$ plants are generally big and well developed, possibly with one or two of the five plants wilting. Subsequently the plants were uprooted and adhering soil was removed from the main and lateral roots. After removing most soil, the roots were rinsed in water to allow observation of the root damage. The numbers of $D$. radicum larvae and pupae were counted. Both the surface of the main roots and the removed soil were carefully checked for larvae or pupae.

\section{Comparing egg and larval infestation}

Prior to the greenhouse resistance test, two accessions-B. oleracea var. acephala (College of Agriculture at Križevci, Croatia, accession A) and $B$. oleracea var capitata cv. Christmas Drumhead,
Table 1 List of 16

Brassica species and numbers of accessions used in the no-choice field screen, and chromosome numbers for each species

* Source: (1) Prakash et al. (1999); (2) Warwick et al. (2009)

\begin{tabular}{lrcc}
\hline Species & No. of accessions tested & No. haploid chromosomes (n) & Source* \\
\hline B. balearica & 3 & 16 & 1 \\
B. bourgeaui & 2 & 9 & 2 \\
B. cretica & 11 & 9 & 2 \\
B. drepanensis & 2 & 9 & 2 \\
B. fruticulosa & 22 & 8 & 1 \\
B. hilarionis & 1 & 9 & 2 \\
B. incana & 13 & 9 & 2 \\
B. insularis & 2 & 9 & 1 \\
B. macrocarpa & 5 & 9 & 2 \\
B. maurorum & 3 & 8 & 1 \\
B. montana & 7 & 9 & 2 \\
B. oleracea & 9 & 9 & 2 \\
B. rupestris & 3 & 9 & 2 \\
B. spinescens & 3 & 8 & 1 \\
B. sylvestris & 1 & 9 & 2 \\
B. villosa & 7 & 9 & 2 \\
Total \# accessions & 94 & & \\
\hline
\end{tabular}


(Centre of Genetic Resources, The Netherlands, accession CGN14080)—were tested using either egg or larval infestation. Seeds were germinated on moist filter paper in a Petri dish. Germinated seeds were then planted into $\varnothing 6 \mathrm{~cm}$ Jiffy ${ }^{\circledR}$ pots with potting compost (Online Resource 2). After three weeks, young plants were transplanted into $\varnothing 14 \mathrm{~cm}$ pots with the same substrate. After transplanting, plants were grown in the greenhouse $\left(22 \pm 2{ }^{\circ} \mathrm{C}\right.$, RH $60 \%$, photoperiod of

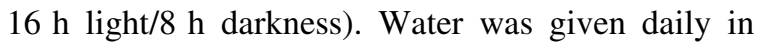
saucers under the pots, and was taken up by the plants through holes in the bottom of the pots. Nutrient solution (Online Resource 2) was given weekly in the same way as watering. Neither insecticides nor other chemicals were applied to the plants. Egg infestation was done as described for the field infestation. The larval infestation was done by placing neonate larvae (hatched from the egg no longer than one day before) on the moist potting soil surface, close to the stem. The larvae were observed crawling into the soil. Twenty eggs or larvae were inoculated on each plant. Eight plants per accession were infested by each method.

\section{Greenhouse resistance test}

Based on the field test results obtained in 2012, accessions with on average less than one D. radicum larva or pupa per plant were considered putatively resistant (Online Resource 1). From each species, at least one accession was selected and subjected to a detailed resistance test in the greenhouse. The accessions were selected using the following criteria (compared to all the other accessions of the same species): 1. The lowest number of plants showing wilting, collapse or death; 2 . Highest plant vigour; 3 . Lowest number of negative remarks on plant development (e.g. 'extremely small plant').

In mid-January 2013, 16 accessions were sown, including 13 accessions of wild Brassica species that were selected as putatively resistant, and three $B$. oleracea cultivars/accessions. Brassica oleracea BOL2010-0437 (B. oleracea Rapid Cycler) and B. oleracea CGN14080 (B. oleracea cv. Christmas Drumhead) were used as susceptible controls. Brassica oleracea var. acephala Accession A was not tested in the field, but was included because a successful cross between $B$. fruticulosa and
B. oleracea var. acephala Accession A had been made (Pelgrom et al. 2015). Seed germination and plant growing conditions were the same as described in the experiment comparing larval and egg infestation.

Twelve seedlings per accession were germinated. Out of these seedlings ten were randomly picked and potted, and were subsequently tested. The infestation was done as described in the no-choice field experiment. Wilting of plants was scored starting one week after infestation. Three weeks after infestation, each plant was enclosed in a textile sleeve to entrap eclosing flies. Adult flies eclosed from each plant were collected daily and counted until no more flies eclosed during seven days. Flies collected per plant were stored at $-20{ }^{\circ} \mathrm{C}$ and transferred individually into Eppendorf tubes for drying at $50{ }^{\circ} \mathrm{C}$ for two days. Dry weight of the flies was measured using a Sartorius ${ }^{\circledR}$ CP2P-F Micro Balance.

At the end of the experiment, plants were taken out of the pots and the roots were cleaned with water. Plant shoot vigour was scored semi-quantitatively on a scale from 0 to 5 , where $0=$ dead plant with no green leaf left; $1=1 / 5$ of the leaves and stems are green, plant collapsed; $2=2 / 5$ of the leaves and stems are green, plant collapsed, $3=3 / 5$ leaves and stems are green, main stem stands up-right; $4=4 / 5$ leaves and stems are green, plant stands up-right with a few leaves collapsed/wilted; $5=$ plant is well developed, all the leaves and stems are green/only a few leaves are partly wilted/yellow, plant stands up-right. Root vigour was also scored semi-quantitatively on a scale from 0 to 2 , where $0=$ no main root left, fine roots hardly found; $1=$ small main roots and several fine roots; $2=$ strong main roots and numerous fine roots. Root damage was scored on a semi-quantitative scale modified after Dosdall et al. (1994) where $0=$ no root damage; $1=$ small feeding channels on the root comprising less than $10 \%$ of the root surface area; $2=11-25 \% ; 3=26-50 \% ; \quad 4=51-75 \%$ and $5=76-100 \%$ of the tap root surface area; $6=$ root is damaged deep into its core tissues and only a small core of the tap root is left. It should be noted that a root surface damage score of 5 did not necessarily indicate a dead plant, as a large part of the root core is still functional and some plants may regrow new roots, while a root damage score of 6 often resulted in a dead plant. Finally plants were oven-dried at $70{ }^{\circ} \mathrm{C}$ for 2 days and the dry weight of each plant was measured. 
Statistical analysis

For the field experiment, the fraction of pupae or larvae retrieved was transformed as $\mathrm{y}=\arcsin$ $(\operatorname{sqrt}(\mathrm{x}))$ and subjected to Analysis of Variance (ANOVA). Accession means were calculated for number of larvae and pupae, plant vigour, number of days until wilting and number of days until collapse. The mean number of days until wilting or collapse was calculated based on the actual number of plants that wilted or collapsed. For the greenhouse experiment, fraction of total flies eclosed, average fly dry weight, days before the first fly eclosion, eclosion period, i.e. the number of days during which flies eclosed (from the first till the last fly eclosing), root damage, shoot vigour, root vigour, plant dry weight, and days before plant wilting were analysed by ANOVA and means separated using Fisher's least significant difference (LSD). Fly eclosion was expressed as fraction of eclosed flies out of number of infested eggs. This fraction was transformed into $\arcsin (\operatorname{sqrt}(\mathrm{x}))$ to stabilize variance. To analyse the effect of different infestation methods a two-way ANOVA was used, with two factors- the effect of infestation method and the effect of accession. For the larva and egg infestation trial parameters analysed included number of flies eclosed, the number of days before the first fly eclosed, and eclosion period. A log transformation was applied to eclosion period in order to stabilize variance. The other parameters showed normal distribution. For statistical calculations IBM SPSS Statistics for Windows (Released 2011, Version 20.0. Armonk, NY: IBM Corp.) and GenStat (17th edition, VSN International Ltd, United Kingdom) were used.

\section{Results}

Field experiment

The aim of the field experiment was to identify accessions putatively resistant to $D$. radicum. Out of the 94 accessions tested, which belonged to 16 Brassica species (Table 1), 36 had zero D. radicum and 25 accessions had on average less than one $D$. radicum pupa or larva per plant (Online Resource 1). Accessions on which no D. radicum larvae or pupae were found belonged to several wild species, including the biennial species $B$. balearica, $B$. cretica, $B$. drepanensis, B. hilarionis, B. incana, B. macrocarpa, $B$. villosa, and the early-flowering annual species $B$. fruticulosa and $B$. spinescens. Fourteen out of a total of 22 accessions of $B$. fruticulosa were free of $D$. radicum larvae or pupae. Among all 94 accessions, in 52 at least one of the five plants wilted, in 10 accessions at least one plant collapsed and in 4 accessions at least one plant died. The proportions of wilted, collapsed, and dead plants within each accession are shown in Online Resource 1 . The number of retrieved D. radicum larvae or pupae did not show significant correlations with either plant vigour, nor the number of days until plant wilting/collapse.

Comparing egg and larval infestation

Comparison of the infestation methods in the greenhouse showed no significant differences in the number of flies eclosed and in the length of the eclosion period (Table 2). Also, no interaction effects were detected for these two parameters. The effect of infestation method and the interaction effect infestation methods with accession were significant for the number of days before the first fly eclosion. The means of the number of flies eclosed from plants infested with eggs or larvae, are given in Online resource 3.

Greenhouse resistance test

From the field experiment, the 13 most resistant accessions were selected for confirmation under greenhouse conditions. Significantly lower proportions of root fly adults eclosed on the accessions $B$. fruticulosa PI663081 and B. spinescens BRA2994 (mean $1 \%$ ) than on the other accessions (Table 3). A moderate proportion of eclosed flies was found on $B$. fruticulosa BRA1727 and B. hilarionis HRIGRU12483, yet they were not significantly different from a few other accessions. Within several accessions a few individual plants were found from which no flies eclosed (Table 3), although the mean number of flies of these accessions was high. For example, within $B$. macrocarpa BRA2944 and B. villosa BRA2922 respectively, one plant was found free of $D$. radicum. A large variation in mean fly dry weight (1.3-2.9 mg) was observed among the accessions (Table 3). Flies with the smallest dry weight developed on $B$. spinescens BRA2994 and B. fruticulosa BRA1727. Flies eclosed on B. fruticulosa PI663081, B. hilarionis 
Table 2 Two-way ANOVA results to assess the effect of infestation methods (larvae or eggs) and accession (B. oleracea CGN14082 and B. oleracea CGN14082) on fly survival and eclosion

\begin{tabular}{lccc}
\hline Trait & $P$ value infestation method effect & P value accession effect & P value interaction effect \\
\hline Number of flies eclosed & 0.706 & 0.409 & 0.711 \\
Days before eclosion $^{\mathrm{a}}$ & $<0.0001$ & 0.106 & 0.014 \\
Eclosion period $^{\mathrm{b}}$ & 0.340 & 0.082 & 0.556 \\
\hline
\end{tabular}

Twenty eggs or larvae, both were one-day old, were used to infest each plant. Eight plants per accession were used

a Number of days of $D$. radicum development from the day of infestation until eclosion of the first fly

b Number of days between the first and the last fly eclosing

Table 3 Accession means of insect characteristics and the number of individual plants (out of 10 tested plants) with zero D. radicum, greenhouse resistance test

\begin{tabular}{|c|c|c|c|c|c|c|}
\hline \multirow[t]{2}{*}{ Species } & \multirow[t]{2}{*}{ Accession } & \multicolumn{4}{|l|}{ Insect trait } & \multirow{2}{*}{$\begin{array}{l}\text { Number of individual } \\
\text { plants with zero } \\
\text { D. radicum }\end{array}$} \\
\hline & & $\begin{array}{l}\text { Total flies eclosed } \\
\text { (fraction) }^{\mathrm{a}}\end{array}$ & $\begin{array}{l}\text { Fly dry } \\
\text { weight (mg) }\end{array}$ & $\begin{array}{l}\text { Days before first } \\
\text { fly eclosion }\end{array}$ & $\begin{array}{l}\text { Eclosion } \\
\text { period }\end{array}$ & \\
\hline B. bourgeaui & BRA2848 & $0.32 \mathrm{~cd}^{\mathrm{b}}$ & $2.9 \mathrm{ef}$ & $32.3 \mathrm{abc}$ & $3.5 b c$ & 1 \\
\hline B. cretica & PI662588 & $0.26 \mathrm{bcd}$ & $2.5 \mathrm{de}$ & 32.6abcd & $4.4 \mathrm{~cd}$ & 1 \\
\hline B. drepanensis & BRA3093 & $0.30 \mathrm{bcd}$ & $2.9 \mathrm{ef}$ & $33.0 \mathrm{bcdef}$ & $3.7 \mathrm{bc}$ & 2 \\
\hline B. fruticulosa & PI663081 $^{c}$ & $0.01 \mathrm{a}$ & $1.7 \mathrm{ab}$ & $32.5 \mathrm{abcd}$ & $1.2 \mathrm{a}$ & 7 \\
\hline B. fruticulosa & BRA1727 & $0.12 b$ & $1.3 \mathrm{a}$ & $31.3 \mathrm{a}$ & $3.7 \mathrm{bc}$ & 4 \\
\hline B. hilarionis & HRIGU12483 & $0.17 b c$ & $2.0 \mathrm{bc}$ & $32.2 \mathrm{abc}$ & $1.9 \mathrm{ab}$ & 2 \\
\hline B. incana & BRA2856 & $0.34 \mathrm{~cd}$ & $2.7 \mathrm{ef}$ & 32.9abcde & $4.5 \mathrm{~cd}$ & 0 \\
\hline B. incana & PI435898 & $0.43 d$ & $2.9 \mathrm{ef}$ & $32.5 \mathrm{abcd}$ & $4.9 \mathrm{~cd}$ & 0 \\
\hline B. macrocarpa & O-502 & $0.30 \mathrm{bcd}$ & $2.9 \mathrm{ef}$ & 33.7cdefg & $4.4 \mathrm{~cd}$ & 0 \\
\hline B. macrocarpa & BRA2944 & $0.33 \mathrm{~cd}$ & $3.1 \mathrm{f}$ & $33.0 \mathrm{bcdef}$ & $4.3 \mathrm{~cd}$ & 1 \\
\hline B. montana & BRA2950 & $0.32 \mathrm{~cd}$ & $2.6 \mathrm{e}$ & $34.4 \mathrm{efg}$ & $4.8 \mathrm{~cd}$ & 1 \\
\hline B. spinescens & BRA2994 & $0.01 \mathrm{a}$ & $1.3 \mathrm{a}$ & $34.6 \mathrm{fg}$ & $3.9 \mathrm{c}$ & 9 \\
\hline B. villosa & BRA2922 & $0.27 \mathrm{bcd}$ & $2.1 \mathrm{~cd}$ & $35.0 \mathrm{~g}$ & $4.7 \mathrm{~cd}$ & 1 \\
\hline B. oleracea & Accession A & $0.18 b c$ & $2.6 \mathrm{e}$ & 34.1defg & $4.0 \mathrm{~cd}$ & 3 \\
\hline B. oleracea & BOL2010-0437 & $0.36 \mathrm{~cd}$ & $2.6 \mathrm{de}$ & 32.7abcde & $4.9 \mathrm{~cd}$ & 0 \\
\hline B. oleracea & CGN14080 & $0.44 d$ & $2.7 \mathrm{ef}$ & $31.8 \mathrm{ab}$ & $5.8 \mathrm{~d}$ & 0 \\
\hline
\end{tabular}

$\overline{{ }^{a}}$ Arcsin(sqrt(fraction)) of number of eclosed flies used for ANOVA was back-transformed to fraction eclosed flies. Twenty eggs were infested per plant

b Means followed by the same letter are not significantly different $(\mathrm{P}>0.05)$ according to Fisher's Least Significant Difference (LSD) test

c Brassica fruticulosa PI663081 and B. spinescens BRA2994 have been typeset in bold to indicate that the fraction of total flies eclosed differed significantly from all other accessions

HRIGU12483 and B. villosa BRA2922 showed intermediate dry weight $(1.7-2.1 \mathrm{mg})$. On the remaining accessions flies had a higher dry weight $(>2.2 \mathrm{mg})$. The reference accessions of B. oleracea BOL20100437 (B. oleracea Rapid Cycler) and B. oleracea CGN14080 (B. oleracea cv. Christmas Drumhead), produced the highest proportion of eclosed flies among all tested accessions (36 and $44 \%$ ), with relatively high average fly dry weight $(2.6-2.7 \mathrm{mg})$. Accessions of several other Brassica species had statistically similar values. Brassica oleracea acephala Accession A produced a low proportion of eclosed flies (18\%), 
but $80 \%$ of the plants wilted. The number of days until fly eclosion ranged from 31.3 days (B. fruticulosa BRA1727) to 35 (B. villosa BRA2922) and the fly eclosion period from 1.2 to 5.8 days (Table 3 ).

The root damage score shows that more than $25 \%$ root surface area was damaged in all the accessions (Table 4). The roots of B. oleracea BOL2010-0437 were damaged most seriously, nearly all the tap roots were consumed. The two accessions on which the lowest proportion of flies eclosed, B. fruticulosa PI663081 and B. spinescens BRA2994, also showed high root damage score. The lowest root damage scores were found on accession $B$. bourgeaui BRA2848 (3.1) and on B. oleracea Accession A (3.2).

The accessions on which it took the longest time before the plants started wilting were $B$. fruticulosa
BRA1727, B. villosa BRA2922 and B. incana BRA2856. Among these three, the proportion of wilted plants was high on B. incana BRA2856 and low on the other two. Brassica fruticulosa PI663081 and $B$. macrocarpa BRA2944 also belonged to the group with the longest period until wilting, but this was not significantly different from several other accessions. All 16 accessions tested in the greenhouse experiment showed symptoms of wilting. Out of these, only seven accessions showed symptoms of wilting in the field experiment, with a maximum of two plants out of five tested. The other eight accessions did not show wilting in the field. Unlike most other tested accessions, the reference cultivar B. oleracea CGN14080 supported more root flies in the field than in the greenhouse test (Online Resource 1, Table 3).

Table 4 Accession means of plant characteristics, greenhouse resistance test

\begin{tabular}{|c|c|c|c|c|c|c|c|}
\hline \multirow[t]{2}{*}{ Species } & \multirow[t]{2}{*}{ Accession } & \multicolumn{6}{|l|}{ Plant trait } \\
\hline & & $\begin{array}{l}\text { Root } \\
\text { damage }^{a}\end{array}$ & $\begin{array}{l}\text { Shoot } \\
\text { vigour }^{\mathrm{b}}\end{array}$ & $\begin{array}{l}\text { Root } \\
\text { vigour }^{\mathrm{c}}\end{array}$ & $\begin{array}{l}\text { Plant dry } \\
\text { weight }(\mathrm{g})\end{array}$ & $\begin{array}{l}\text { Days until } \\
\text { wilting }\end{array}$ & $\begin{array}{l}\% \text { wilted } \\
\text { plants }\end{array}$ \\
\hline B. bourgeaui & BRA2848 & $3.1 \mathrm{a}^{\mathrm{d}}$ & $4.3 \mathrm{ef}$ & 1.8def & $9.5 \mathrm{ef}$ & $14 a b c$ & 100 \\
\hline B. cretica & PI662588 & $5.3 \mathrm{cde}$ & $2.3 \mathrm{ab}$ & $0.6 \mathrm{a}$ & $4.6 a b c$ & $12 \mathrm{a}$ & 100 \\
\hline B. drepanensis & BRA3093 & $4.4 \mathrm{bc}$ & $3.3 \mathrm{bcde}$ & $1.5 \mathrm{bcde}$ & $6.4 \mathrm{bcd}$ & $14 a b c$ & 50 \\
\hline B. fruticulosa & PI663081 $^{\mathrm{e}}$ & $5.4 \mathrm{cde}$ & $4.8 \mathrm{f}$ & $1.9 \mathrm{ef}$ & $6.2 \mathrm{abcd}$ & $18 \mathrm{ef}$ & 50 \\
\hline B. fruticulosa & BRA1727 & $5.6 \mathrm{de}$ & $4.3 \mathrm{ef}$ & $1.9 \mathrm{ef}$ & $7.2 \mathrm{cde}$ & $20 \mathrm{f}$ & 30 \\
\hline B. hilarionis & HRIGU12483 & 5 bcde & $2.1 \mathrm{a}$ & $0.9 \mathrm{ab}$ & $3.3 \mathrm{a}$ & $14 a b c$ & 44 \\
\hline B. incana & BRA2856 & $4.7 \mathrm{bcd}$ & $3.9 \mathrm{def}$ & $1.7 \mathrm{cde}$ & 7.4cde & $19 f$ & 90 \\
\hline B. incana & PI435898 & $4.6 \mathrm{bcd}$ & 3 abcd & 1.1abcd & 7.6de & $15 \mathrm{abc}$ & 80 \\
\hline B. macrocarpa & O-502 & $5.3 \mathrm{cde}$ & $3.8 \mathrm{cdef}$ & $1.5 \mathrm{bcde}$ & $5.5 \mathrm{abcd}$ & $16 b c d e$ & 75 \\
\hline B. macrocarpa & BRA2944 & 5 bcde & 3.3bcde & 1.2abcde & 6.1abcd & 18def & 20 \\
\hline B. montana & BRA2950 & $5.3 \mathrm{cde}$ & $3.3 \mathrm{bcde}$ & $1.5 \mathrm{bcde}$ & $6.3 \mathrm{bcd}$ & $16 \mathrm{cde}$ & 60 \\
\hline B. spinescens & BRA2994 ${ }^{\mathrm{e}}$ & $4.5 \mathrm{bc}$ & $3.7 \mathrm{cde}$ & $1 \mathrm{abc}$ & $4.3 \mathrm{ab}$ & $16 \mathrm{bcde}$ & 70 \\
\hline B. villosa & BRA2922 & $4.6 b c$ & $4.2 \mathrm{ef}$ & $2.4 \mathrm{f}$ & $7.2 \mathrm{cde}$ & $20 \mathrm{f}$ & 50 \\
\hline B. oleracea & Accession A & $3.2 \mathrm{a}$ & $4 \mathrm{def}$ & $1.9 \mathrm{ef}$ & $11.6 \mathrm{f}$ & $17 \mathrm{cde}$ & 80 \\
\hline B. oleracea & BOL2010-0437 & $6 \mathrm{e}$ & $2.7 \mathrm{abc}$ & $0.6 \mathrm{a}$ & $5.3 \mathrm{abcd}$ & $15 \mathrm{bcd}$ & 70 \\
\hline B. oleracea & CGN14080 & $4.1 \mathrm{ab}$ & $3.9 \mathrm{def}$ & $1.4 \mathrm{bcde}$ & $9.7 \mathrm{ef}$ & $14 \mathrm{ab}$ & 100 \\
\hline
\end{tabular}

${ }^{a}$ Root damage was scored on a modified semi-quantitative scale (Dosdall et al. 1994) where $0=$ no root damage; $1=$ small feeding channels on the root comprising less than $10 \%$ of the root surface area; $2=11-25 \% ; 3=26-50 \% ; 4=51-75 \%$ and $5=76-100 \%$ of the tap root surface area; $6=$ Root is damaged deeply and only a small core of the tap root left

b Plant shoot vigour was scored semi-quantitatively on a scale from 0 to 5 (very poor/dead-well developed, see Materials and Methods section Greenhouse resistance test.)

${ }^{c}$ Root vigour was scored semi-quantitatively on a scale from 0 to 2 (no root/dead - good root system, see Materials and Methods section Greenhouse resistance test.)

d Means followed by the same letter are not significantly different $(\mathrm{P}>0.05)$ according to Fisher's least significant difference (LSD) test

e Brassica fruticulosa PI663081 and B. spinescens BRA2994 have been typeset in bold to indicate that the fraction of total flies eclosed differed significantly from all other accessions 
Correlations between traits were detected using accession means and individual plant data (Table 5, Online resource 4). Among insect traits, a few significant correlations were found. Based on the accession means, the number of flies eclosed showed a strong positive correlation with fly dry weight (Table 5; Fig. 1) and with eclosion period. These two correlations were also significant when calculated based on individual plant data (Online resource 4). Individual plant data also showed a negative correlation between the number of flies eclosed and the days before the first fly eclosion (Online resource 4).

Among plant traits, several significant correlations were found. The accession means and individual plant data showed that shoot vigour, root vigour and plant dry weight were positively correlated with each other; plant dry weight was negatively correlated with root damage. For individual plant data, root damage was also negatively correlated with shoot vigour and root vigour. The number of days until wilting was positively correlated with both shoot and root vigour in both accession means and individual plant data. Besides, individual plant data also showed that days until wilting was correlated positively with plant dry weight. The percentage of wilted plants per accession showed no significant correlation with any other trait.

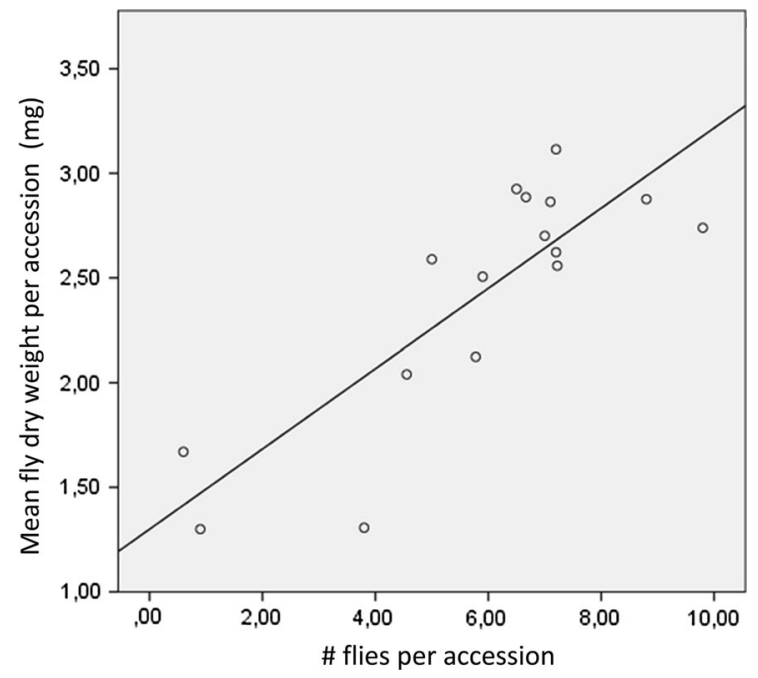

Fig. 1 Scatter plot of the number of flies retrieved per accession and mean fly dry weight per accession (Spearman's rho $0.71, \mathrm{P}<0.0001$ )

Some insect traits showed correlations with the plant traits based on individual plant data. The number of flies eclosed was negatively correlated with shoot and root vigour and plant dry weight. The number of flies was positively correlated with the average root damage. The number of days until the first fly eclosion was positively correlated with root vigour, plant dry

Table 5 Spearman's correlation coefficient between parameters of the greenhouse test, based on accession means

\begin{tabular}{|c|c|c|c|c|c|c|c|c|c|}
\hline & $\begin{array}{l}\text { Fly dry } \\
\text { weight }\end{array}$ & $\begin{array}{l}\text { Days before fly } \\
\text { eclosion }\end{array}$ & $\begin{array}{l}\text { Eclosion } \\
\text { period }\end{array}$ & $\begin{array}{l}\text { Root } \\
\text { damage }\end{array}$ & $\begin{array}{l}\text { Shoot } \\
\text { vigour }\end{array}$ & $\begin{array}{l}\text { Root } \\
\text { vigour }\end{array}$ & $\begin{array}{l}\text { Plant dry } \\
\text { weight }\end{array}$ & $\begin{array}{l}\text { Days before } \\
\text { wilting }\end{array}$ & $\begin{array}{l}\% \text { Wilted } \\
\text { plants }\end{array}$ \\
\hline $\begin{array}{l}\text { Fraction of flies } \\
\text { eclosed }\end{array}$ & $0.71 * *$ & -0.05 & $0.75 * *$ & -0.13 & -0.38 & -0.36 & 0.31 & -0.34 & 0.32 \\
\hline Fly dry weight & & 0.05 & 0.31 & -0.33 & -0.10 & -0.06 & 0.36 & -0.23 & 0.28 \\
\hline $\begin{array}{l}\text { Days before first } \\
\text { fly eclosion }\end{array}$ & & & 0.23 & -0.16 & -0.06 & 0.11 & -0.12 & 0.33 & -0.10 \\
\hline $\begin{array}{l}\text { Days of fly } \\
\text { eclosion }\end{array}$ & & & & 0.05 & -0.29 & -0.27 & 0.23 & -0.03 & 0.38 \\
\hline Root damage & & & & & -0.25 & -0.23 & $-0.57 *$ & 0.23 & -0.41 \\
\hline Shoot vigour & & & & & & $0.88 * *$ & $0.57 *$ & $0.55^{*}$ & 0.04 \\
\hline Root vigour & & & & & & & $0.612 *$ & $0.64 * *$ & -0.14 \\
\hline Plant dry weight & & & & & & & & 0.18 & 0.40 \\
\hline $\begin{array}{l}\text { Days before } \\
\text { wilting }\end{array}$ & & & & & & & & & -0.47 \\
\hline
\end{tabular}

* Correlation is significant at the 0.05 level (2-tailed)

** Correlation is significant at the 0.01 level (2-tailed)

$\mathrm{N}=16$ 
weight, and days until wilting. Neither the number of days until wilting nor the percentage wilted plants showed a significant correlation with the proportion of eclosed flies.

No correlation was detected between the wiltingrelated parameters in the field and any parameters in the greenhouse (Online resource 5), although the accessions that produced the lowest proportion of eclosed flies in the greenhouse test showed no wilting in the field. However, some of the accessions without wilting symptoms in the field did produce flies in the greenhouse (Online Resource 1).

\section{Discussion}

Resistance screening methodology

\section{Egg versus larval infestation}

Egg infestation is easy to handle in practice and is less labour-intensive than larval infestation. Recent studies showed that herbivore eggs affect plant direct and indirect defence (Hilker and Fatouros 2015). Although in nature $D$. radicum lays its eggs not directly in contact with the plant (Zohren 1968 cited in Schoonhoven et al. 2005), root exudates contain secondary metabolites (Schreiner et al. 2011) that could potentially influence egg development and survival. Therefore we tested both egg and larval infestation using two accessions. We found no significant difference in the proportion of adult flies eclosing between the two infestation methods. Since egg infestation did not differ from larval infestation for antibiosis resistance screening under greenhouse conditions, egg infestation was chosen as the standard method.

\section{Parameters for resistance screens}

The proportions of successfully developing larvae and pupae are commonly used to assess the level of antibiosis resistance to D. radicum (Finch and Ackley 1977; Ellis et al. 1999; Jyoti et al. 2001; Felkl et al. 2005). In the field experiment we collected larvae and pupae from the soil around the root system. In the greenhouse experiment we employed a new parameter-the proportion of eclosed flies-for antibiosis assessment. Instead of uprooting the plants and collecting larvae or pupae, we allowed the pupae staying underground undisturbed until adult flies eclosed. There are several advantages of using this method compared to counting larvae/pupae. Firstly, it includes the possible effect of the plant on pupal mortality/development. Some researchers collected pupae and evaluated fly eclosion under artificial conditions (Jyoti et al. 2001; Felkl et al. 2005), which excluded the possible effect of the plant root environment on pupal survival. Felkl et al. (2005) reported the fraction of flies that eclosed from pupae to range from 0.82 to 0.99 for the four tested $B$. fruticulosa accessions, and 0.85 for B. oleracea BOL2010-0437. Secondly, it allows to assess the development of $D$. radicum more accurately. The pupal stage lasts 3 weeks, thus it is hard to estimate pupal age when pupae are found. By using eclosed flies we can obtain precise data on the days elapsed before eclosion, and the eclosion period. Thirdly, it avoids the risk of overlooking larvae or pupae in the soil and the labour involved in searching for them. Eclosed flies were trapped in sleeves and thus were easy to collect. Instead of measuring the weight of pupae and larvae (Jyoti et al. 2001), dry weight of adult flies was measured in our greenhouse experiment as another parameter for insect development and growth. Although not conducted in this research, using eclosed flies also provides the possibility to assess the fecundity of females allowing to predict population development of $D$. radicum on a particular accession.

The fraction of eclosed flies developed from the 20 inoculated eggs per plant ranged from 0.01 to 0.44 , which is comparable to the survival rate from nochoice resistance screens in previous studies. In the study of Felkl et al. (2005), the highest D. radicum pupae recovery was $\sim 15 \%$ on the cauliflower $B$. oleracea var. botrytis cv. Fremont. In the study of Jyoti et al. (2001), the highest larval survival was $31 \%$ on the cauliflower $B$. oleracea var. botrytis $\mathrm{cv}$. Amazing, and the highest pupal recovery rate of $\sim 22 \%$ was found on the broccoli B. oleracea var. italica cv. Green Comet. In the study of Finch and Ackley (1977), 18 and $38 \%$ of inoculated eggs produced pupae on $B$. oleracea when infested at different plant ages. The papers cited above used 10-20 eggs for infestation. It is possible that infestation with a higher number of eggs would give stronger effects on the plant phenotype. However, it should be noted that larval feeding damage was observed on 
almost all the accessions, including on the most resistant ones. A higher infestation pressure might lead to early plant mortality due to a quick consumption of the root system, as well as the loss of the part of the insects due to severe competition. To avoid this, an infestation with 20 eggs was used.

Parameters of plant performance are vital for breeders and have been used in the literature as a tool for selecting resistant plant material. Root damage is an important parameter for antibiosis, especially in determining whether plants supported early larval development yet not sufficiently to develop into pupae. Root damage and root vigour give a good indication of the extent of larval damage and plant performance respectively. Plant vigour and plantmorphological traits show high variation within an accession. Plants with higher root and shoot vigour might have a certain level of tolerance to the insect damage (Painter 1941; Acquaah 2012).

Wilting and collapse are typical symptoms of Brassica plants damaged by cabbage root fly larvae. Jensen et al. (2002) studied the resistance of 14 accessions of $B$. fruticulosa by evaluating the number of days before plant wilting or collapse after root fly infestation and plant survival, and found $B$. fruticulosa in general survived more days without collapse compared to B. oleracea. Ellis et al. (1999) reported high (B. fruticulosa, B. incana, B. spinescens) and moderate (B. macrocarpa and B. villosa) levels of antibiosis resistance, using the number of pupae together with the parameters "percentage of damaged plants per accession", "the mean time to collapse", and "the mean time to $50 \%$ collapse". In our experiments parameters related to wilting proved to be unreliable as criteria for quantifying resistance. Firstly, plants of different species/accessions vary in leaf morphology, including the toughness of leaves, which may influence the phenotype of wilting under the same root fly pressure. Brassica spinescens and $B$. fruticulosa both have a small total leaf area which may reduce transpiration rate and wilting (assuming equal number of stomata per unit leaf surface of all accessions), making it questionable to compare these species with other species with a larger leaf area. Secondly, the symptoms of wilting over time also vary between accessions. For example, B. oleracea BOL2010-0437 typically showed early wilting of the old and young leaves which was soon followed by the collapse of the entire plant including wilting of the flowers. In contrast, B. fruticulosa and B. spinescens usually showed wilting of a few old leaves subsequently resulting in yellowing and loss of these leaves, while wilting of young leaves and plant collapse was not observed. Thirdly, wilting symptoms can be caused by other reasons such as drought as well as other pests and pathogens in the field. Thus "wilting" solely cannot be used as a criterion for antibiosis resistance among different species/accessions, although it can serve as a measure of tolerance.

The insect parameters that we used primarily related to antibiosis, as they directly measure the mortality, growth and development of the insect. The plant parameters focus on plant growth and tolerance during or after larval feeding. In general it was remarkable that no significant correlation was found between the plant and insect related parameters based on accession means. Yet based on individual plant data, some significant correlations were found (Online resource 4), for example the fraction of eclosed flies correlated with all the other insect and plant traits except with days until plant wilting. Variation within accessions may explain why correlations among accession means were not significant. Root vigour and shoot vigour showed strong positive correlation suggesting that they measure the same underlying trait relevant to rootfly tolerance. Wilting can be the result of root fly damage, but we found no correlation between wilting and insect parameters. Again we conclude that wilting is more relevant to tolerance, as accessions with high level of tolerance could show delayed wilting or a low proportion of wilted plants.

For future antibiosis resistance screenings, we propose a methodology including the scoring of the number of eclosed $D$. radicum (preferably adult, or larvae/pupae), root damage level, and the shoot or root vigour. Insect survival should be the key parameter, as it determines the growth of the insect population. Quantifying the fraction of eclosed flies provides more informative data and is practical when testing plants in pots. To predict population development of $D$. radicum on a particular accession, it would be useful to sex the eclosed flies, and collect the fecundity data of the females. Root damage provides direct evidence of larval feeding. Both shoot and root vigour provide valuable information on plant tolerance to root fly attack. Both field and greenhouse screens are essential in identifying antibiosis among wild Brassica species. No-choice field screening is a realistic, economical 
and efficient method for identifying potentially resistant candidates among many accessions. To avoid missing larvae/pupae and reduce the effect of predators, a field experiment could be replaced by a potted plant experiment outdoors, using big pots filled with substrate and sand. A greenhouse test is important to confirm the resistance and susceptibility of plants in a controlled environment. One issue that also should be noted is the fact that we used a $D$. radicum population that was maintained under laboratory conditions for many years. This may have resulted in selection of a genotype best adapted to these conditions, which is probably different from the original field collection. For a more thorough confirmation of the selected accessions, a test using more $D$. radicum populations is highly recommended.

\section{Comparison of field and greenhouse experiments}

A no-choice approach was applied in the field experiment. This approach differs from most literature on $D$. radicum resistance in which no-choice tests were often conducted in the greenhouse, complementing choice tests in the field (Finch and Ackley 1977; Ellis et al. 1999; Jyoti et al. 2001). Given a choice, female root flies prefer to oviposit on some $B$. oleracea accessions over others (Dosdall et al. 1994; Finch and Ackley 1977; Ellis et al. 1999; Jyoti et al. 2001), but in large monoculture fields no such choice is possible. No-choice tests through egg infestation in the field ensured that the selection of resistance was based on antibiosis, not antixenosis. Of course many factors can influence the results in the field, e.g. wild females might lay eggs on pre-infested plants, leading to higher number of larvae/pupae on some accessions. In this case differences in developmental stages may be used to identify plants infested by wild $D$. radicum from the pre-infested $D$. radicum during evaluation, if desired. As we focussed on plants and accessions with the lowest number of insects the ones with more larvae and pupae were not selected.

The testing environment influenced the results considerably, particularly in the number of insects retrieved and in wilting. Greenhouse conditions seemed to be optimal for insect growth as the temperature and moisture level was similar to those prevailing in the D. radicum rearing. Most of the accessions produced higher proportions of eclosed flies in the greenhouse experiment than the proportions of larvae and pupae they produced in the field experiment. Several accessions on which zero $D$. radicum larvae or pupae were found in the field experiment showed varying levels of susceptibility in the greenhouse test. Also, more plants showed wilting in the greenhouse than in the field. In the field, plants are exposed to a more complex biotic and abiotic environment that potentially influences the phenotype. Natural enemies of underground herbivores can be attracted (Van Tol et al. 2001; Rasmann et al. 2005), as some accessions might be more efficient in this type of indirect defence by recruiting more natural enemies. Plant root morphology may also differ considerably between field and greenhouse conditions, possibly affecting the survival and the development of the larvae (Felkl et al. 2005). In addition, differences in soil conditions might also influence herbivore-associated organisms, which subsequently affect insect physiology and the plant phenotype (Zhu et al. 2014). Moreover, environmental conditions may have a large effect on tolerance, resulting in differences in plant performance (Painter 1951).

Inoculation under greenhouse conditions was found suitable to determine cruciferous hosts of $D$. radicum (Finch and Ackley 1977). With strong influence of environment, the choice of appropriate reference accessions becomes important when plants are tested under both field and greenhouse conditions. The $B$. oleracea CGN14080 showed stable performance under both field and greenhouse conditions, in contrast to B. oleracea BOL2010-0437 that showed a more variable result. No larvae or pupae were retrieved from B. oleracea BOL2010-0437 in the field test. In our greenhouse experiment, B. oleracea BOL2010-0437 exhibited the highest number of flies, the highest root damage score and the highest proportion of wilted plants, indicating a combination of low antibiosis and low tolerance (Felkl et al. 2005). In other studies, moderate to low number of $D$. radicum larvae or pupae were found on B. oleracea BOL2010-0437 (Ellis et al. 1999; Jyoti et al. 2001; Jensen et al. 2002; Felkl et al. 2005). Similar to B. oleracea BOL2010-0437, the other early-flowering accessions of $B$. fruticulosa and $B$. spinescens showed relatively high root damage scores. This is partly due to their small root system. As is showed by Felkl et al. (2005), plants with long main roots and a large number of lateral roots often had higher tolerance to root fly damage. The biennial $B$. oleracea CGN14080, although it showed low 
antibiosis and supported a high number of flies, was relatively high in tolerance thus the root damage score was lower than for B. oleracea BOL2010-0437. The larger root system has probably contributed to the high tolerance of CGN14080.

Selection of resistant plants

Accessions with the strongest antibiosis resistance belong to $B$. fruticulosa and B. spinescens. In several studies, antibiosis resistance was identified in accessions of B. fruticulosa (Ellis et al. 1999; Jensen et al. 2002; Felkl et al. 2005). In their studies B. fruticulosa BRA1039 was found to be resistant, and in our field test this accession showed $1 \%$ survival of infested $D$. radicum on average, thus was left out of our greenhouse confirmation test as we selected only the accessions that did not support any $D$. radicum survival. Some B. fruticulosa accessions have shown resistance towards several other insects as well, including the aphid B. brassicae, the cabbage whitefly A. proletella, and the green peach aphid Myzus persicae (Sulzer, 1776) (Hemiptera: Aphididae) (Singh et al. 1994; Ellis et al. 1996, 2000; Pelgrom et al. 2015). Ellis et al. (1999) identified antibiosis resistance to $D$. radicum in B. spinescens CA91061, showing a reduced number of pupae and high plant survival. Accessions of $B$. spinescens also show antibiosis resistance to the cabbage aphid $B$. brassicae (Singh et al. 1994), resistance to white rust Albugo candida [(Pers. ex. Lév.) Kuntze] (Peronosporales: Albuginaceae) and salt tolerance (Kirti et al. 1991), making it an interesting material for breeding. In the greenhouse we identified high levels of resistance to D. radicum in accessions B. fruticulosa PI663081 and $B$. spinescens BRA2994. These accessions also showed a high or moderate level of shoot and root vigour, and reduced fly dry weight. Both the higher insect mortality and the lower fly dry weight indicate that the resistance is based on antibiosis.

Next to the two highly resistant early-flowering species, moderately resistant material was found within the biennial species. In previous studies, high levels of antibiosis to $D$. radicum was found in $B$. incana, and moderate resistance in B. macrocarpa and $B$. villosa, using mainly plant performance parameters (Ellis et al. 1999). In our study of accessions of the same species (Table 3 and Online Resource 1), we found resistant candidates in all of these species in the field screen. Brassica macrocarpa BRA2944 and B. villosa BRA2922 lasted long before wilting, and had a relatively low proportion of wilted plants. Brassica incana BRA2856 also lasted long before wilting, but exhibited a high proportion of wilting plants. All individual plants of the two B. incana accessions produced flies in the greenhouse, though no larvae or pupae were collected from the same accessions in the field experiment. Plants with better general vigour have higher tolerance to insect attack (Painter 1951). Some plants with higher tolerance were able to regrow new roots from the undamaged part of the main root, thus it is likely that tolerance played a role in delaying wilting. The high number of flies and long period before wilting of $B$. incana BRA2856 could be due to low antibiosis, combined with a high level of tolerance to early larval feeding. Within-accession variation in some of these accessions was visible in the greenhouse, for instance in accessions where on some individual plants no root fly developed, while other plants showed a high percentage of eclosed flies (Table 3). Similarly, within-accession variation regarding cabbage aphid resistance has been reported by others as well (Ellis et al. 2000). Because accessions are heterogeneous, the within-accession variation may be genetic. From an accession with a high average fly survival, the plants that showed no root flies emerged may be resistant to $D$. radicum. Such individuals may definitely be interesting for further investigation. Selfings can be made and crosses within the accession and crosses with $B$. oleracea are suggested. The progenies should be screened for antibiosis to $D$. radicum.

In the field evaluation we tested a large number of accessions each with five plants and selected only accessions on which we found no $D$. radicum. Consequently, we have not selected resistant plants in heterogeneous accessions. In the greenhouse test the number of plants per accession was increased to 10 . Also here heterogeneity was evident. Both the lack of correlations based on accession means between insect and plant traits, and the clear within-accession variation observed indicate that more attention should be paid to assessment of individual plants in these wild species related to $B$. oleracea.

Prospects for resistance breeding and use of genes

High levels of antibiosis resistance towards cabbage root flies were identified in two accessions, $B$. 
spinescens BRA2994 and B. fruticulosa PI663081. They showed not only significantly reduced proportions of $D$. radicum eclosing, but also a significantly lower fly dry weight of survivors. These two accessions hold potential for studying the genetics of the resistance and for breeding of resistant cabbages. As genetic modification is not a marketable option in the current European context, it is important that the resistance mechanisms found in related species can be crossed into the cultivated Brassica genome. Both $B$. fruticulosa and B. spinescens ( $\mathrm{n}=8$ and 16) have different chromosome number than $B$. oleracea $(\mathrm{n}=9)$ (Ellis et al. 2000; Jensen et al. 2002), making the transfer of genes from $B$. fruticulosa and $B$. spinescens to $B$. oleracea problematic. To cope with that, advanced interspecific hybridisation techniques such as ovary, ovule and embryo culture (Takeshita et al. 1980; Diederichsen and Sacristan 1988; Bajaj et al. 1986) or protoplast fusion techniques (Kirti et al. 1991) could be helpful. Recently, interspecific hybridization between a $B$. fruticulos $a$ and $B$. oleracea var. acephala has shown to be possible (Pelgrom et al. 2015), although fertility of the hybrid is an issue. The species $B$. villosa, B. incana, B. cretica, B. insularis, $B$. macrocarpa, B. montana, B. rupestris, B. bourgeaui, $B$. hilarionis and $B$. drepanensis belong to the $B$. oleracea complex $(\mathrm{n}=9)$, and interspecific crosses with $B$. oleracea are possible (von Bothmer et al. 1995; Lazaro and Aguinagalde 1998; Faulkner et al. 1998). Among these species we found promising accessions in the field and medium levels of mean number of $D$. radicum in the greenhouse.

To apply the detected resistance in the practice of plant breeding when gene transfer by the afore mentioned methods is possible, might be by identifying resistance QTLs in intra-specific crosses between resistant and susceptible plants and to introgress these QTLs using marker-assisted selection. If gene transfer proves impossible, the homologs of the identified QTLs in B. oleracea, and the allelic variation of the putative causal genes in the $B$. oleracea complex can be investigated. Obviously, a reliable identification of resistant and susceptible parents within the donor species is needed and our work together with the entomological literature cited in the Introduction indicates that this is feasible. Assuming that introgression of the resistance trait into $B$. oleracea is successful, measures should be taken to avoid breakdown of the resistance, crop rotation being one of them. Applying integrated pest management can contribute to control the pest in an environmentally benign way. When more than one resistance gene is found, gene pyramiding may also increase durable resistance (Joshi and Nayak 2010; Li et al. 2014). Antixenosis resistance may also further strengthen antibiosis resistant and tolerant accessions.

Tolerance is a mechanism that supports plant survival and development to minimize fitness loss resulting from insect attack. Plants with high tolerance may be useful in a push-pull system, or in combination with integrated pest management. Yet tolerance supports the insect population to increase until tolerance breaks down. Obviously breeding for tolerance is not useful in controlling insect pests in the long run without incorporating other means of insect control. This is why we did not aim for selecting plants with high tolerance. Strong antibiosis resistance in combination with high tolerance is considered most desirable in our study.

In conclusion, we identified several accessions with medium to high levels of antibiosis resistance towards the cabbage root fly among wild Brassica species. Accessions with the highest levels of resistance belonging to the species $B$. fruticulos $a$ and $B$. spinescens are difficult to cross with $B$. oleracea, but may be promising materials for studying the genetics of the resistance through a QTL mapping approach. Several other accessions (B. villosa BRA2922, B. montana BRA2950, B. hilarionis HRIGU12483, B. macrocarpa BRA2944) with medium level of antibiosis resistance and medium to high level of tolerance are more easily crossed with $B$. oleracea. As variation within accessions was observed, selection of the most resistant individuals within these accessions is important. In the greenhouse, using the proportion of eclosed flies is effective and efficient, thus this scoring method is highly recommended for root fly resistance screens.

Acknowledgments We sincerely thank two anonymous reviewers for their valuable comments on this paper. We are grateful to the Netherlands Organisation for Scientific Research (ALW-NWO), Technological Top Institute Green Genetics (TTI Groene Genetica), Wageningen UR Plant Breeding, Syngenta and Bejo for funding the project. We thank Drs. Noortje Bas of the Centre for Genetic Resources, Wageningen for assistance in obtaining Brassica accessions. We thank Dr. Nicole van Dam and Dr. Guusje A.B. Bonnema for their advice.

Open Access This article is distributed under the terms of the Creative Commons Attribution 4.0 International License 
(http://creativecommons.org/licenses/by/4.0/), which permits unrestricted use, distribution, and reproduction in any medium, provided you give appropriate credit to the original author(s) and the source, provide a link to the Creative Commons license, and indicate if changes were made.

\section{References}

Acquaah G (2012) Principles of plant genetics and breeding. Blackwell Publishing Ltd, Oxford. doi:10.1002/ 9781118313718

Bajaj YPS, Mahajan SK, Labana KS (1986) Interspecific hybridization of Brassica napus and B. juncea through ovary, ovule and embryo culture. Euphytica 35:103-109. doi: $10.1007 /$ bf00028547

Baur R, Birch ANE, Hopkins RJ, Griffiths DW, Simmonds MSJ, Stadler E (1996) Oviposition and chemosensory stimulation of the root flies Delia radicum and D. floralis in response to plants and leaf surface extracts from resistant and susceptible Brassica genotypes. Entomol Exp Appl 78:61-75

Bodnaryk RP (1992) Leaf epicuticular wax, an antixenotic factor in Brassicaceae that affects the rate and pattern of feeding of flea beetles, Phyllotreta cruciferae (Goeze). Can J Plant Sci 72:1295-1303. doi:10.4141/cjps92-163

Bomford MK, Vernon RS, Päts P (2000) Importance of collection overhangs on the efficacy of exclusion fences for managing cabbage flies (Diptera: Anthomyiidae). Environ Entomol 29:795-799. doi:10.1603/0046-225x-29.4.795

Broekgaarden C, Snoeren TAL, Dicke M, Vosman B (2011) Exploiting natural variation to identify insect-resistance genes. Plant Biotechnol J 9:819-825. doi:10.1111/j.14677652.2011.00635.x

Bruck DJ, Snelling JE, Dreves AJ, Jaronski ST (2005) Laboratory bioassays of entomopathogenic fungi for control of Delia radicum (L.) larvae. J Invertebr Pathol 89:179-183. doi:10.1016/j.jip.2005.02.007

Chandler D, Davidson G (2005) Evaluation of entomopathogenic fungus Metarhizium anisopliae against soildwelling stages of cabbage maggot (Diptera: Anthomyiidae) in glasshouse and field experiments and effect of fungicides on fungal activity. $J$ Econ Entomol 98:1856-1862. doi:10.1093/jee/98.6.1856

Coaker TH, Williams DA (1963) The importance of some carabidae and staphylinidae as predators of the cabbage root fly, Erioischia brassicae (bouché). Entomol Exp Appl 6:156-164. doi:10.1111/j.1570-7458.1963.tb00613.x

Diederichsen E, Sacristan MD (1988) Interspecific hybridizations in the genus Brassica followed by ovule embryo culture. Eucarpia Crucif Newsl 13:20-21 Cited in Felkl et al. (2005)

Dosdall LM, Herbut MJ, Cowle NT (1994) Susceptibilities of species and cultivars of canola and mustard to infestation by root maggots (Delia spp.) (Diptera: Anthomyiidae). Can Entomol 126:251-260

Dosdall LM, Good A, Keddie BA, Ekuere U, Stringam G (2000) Identification and evaluation of root maggot (Delia spp.) (Diptera: Anthomyiidae) resistance within Brassicaceae. Crop Prot 19:247-253. doi:10.1016/s0261-2194(00)00015-6
Eenink AH, Dieleman FL (1983) Inheritance of resistance to the leaf aphid Nasonovia ribis-nigri in the wild lettuce species Lactuca virosa. Euphytica 32:691-695. doi:10.1007/ bf00042148

Ekuere UU, Dosdall LM, Hills M, Keddie AB, Kott L, Good A (2005) Identification, mapping, and economic evaluation of QTLs encoding root maggot resistance in Brassica. Crop Sci 45:371-378. doi:10.2135/cropsci2005.0371

Ellis PR, Hardman JA (1975) Laboratory methods for studying nonpreference resistance to cabbage root fly in cruciferous crops. Ann Appl Biol 79:253-264

Ellis PR, Hardman JA, Crisp P, Johnson AG (1976) Laboratory studies of nonpreference resistance to cabbage root fly in radish. Ann Appl Biol 84:81-89

Ellis PR, Hardman JA, Crisp P, Johnson AG (1979) The influence of plant age on resistance of radish to cabbage root fly egg-laying. Ann Appl Biol 93:125-132

Ellis PR, Singh R, Pink DAC, Lynn JR, Saw PL (1996) Resistance to Brevicoryne brassicae in horticultural brassicas. Euphytica 88:85-96. doi:10.1007/bf00032439

Ellis PR, Pink DAC, Barber NE, Mead A (1999) Identification of high levels of resistance to cabbage root fly, Delia radicum, in wild Brassica species. Euphytica 110: 207-214. doi:10.1023/a:1003752801143

Ellis PR, Kift NB, Pink DAC, Jukes PL, Lynn J, Tatchell GM (2000) Variation in resistance to the cabbage aphid (Brevicoryne brassicae) between and within wild and cultivated Brassica species. Genet Resour Crop Evol 47:395-401. doi:10.1023/a:1008755411053

Faulkner K, Mithen R, Williamson G (1998) Selective increase of the potential anticarcinogen 4-methylsulphinylbutyl glucosinolate in broccoli. Carcinogenesis 19:605-609

Felkl G, Jensen EB, Kristiansen K, Andersen SB (2005) Tolerance and antibiosis resistance to cabbage root fly in vegetable Brassica species. Entomol Exp Appl 116:65-71

Finch S (1993) Integrated pest-management of the cabbage root fly and the carrot fly. Crop Prot 12:423-430. doi:10.1016/ 0261-2194(93)90003-2

Finch S, Ackley CM (1977) Cultivated and wild host plants supporting populations of the cabbage root fly. Ann Appl Biol 85:13-22. doi:10.1111/j.1744-7348.1977.tb00626.x

Finch S, Coaker TH (1969) A method for the continuous rearing of the cabbage root fly Erioischia brassicae (Bch.) and some observations on its biology. Bull Entomol Res 58:619-628. doi:10.1017/s0007485300057345

Firdaus S, van Heusden A, Hidayati N, Supena E, Mumm R, de Vos RH, Visser RF, Vosman B (2013) Identification and QTL mapping of whitefly resistance components in Solanum galapagense. Theor Appl Genet 126:1487-1501. doi:10.1007/s00122-013-2067-z

Georgis R et al (2006) Successes and failures in the use of parasitic nematodes for pest control. Biol Control 38:103-123. doi:10.1016/j.bentrl.2005.11.005

Griffiths GCD (1986) Relative abundance of the root maggots Delia radicum (L.) and D. floralis (Fallén) (Diptera: Anthomyiidae) as pests of canola in Alberta. Quaest Entomol 22:253-260

Hilker M, Fatouros NE (2015) Plant responses to insect egg deposition. Annu Rev Entomol 60:493-515. doi:10.1146/ annurev-ento-010814-020620 
Hummel JD, Dosdall LM, Clayton GW, Harker KN, O’Donovan JT (2010) Responses of the parasitoids of Delia radicum (Diptera: Anthomyiidae) to the vegetational diversity of intercrops. Biol Control 55:151-158. doi:10.1016/j. biocontrol.2010.08.004

Jensen EB, Felkl G, Kristiansen K, Andersen SB (2002) Resistance to the cabbage root fly, Delia radicum, within Brassica fruticulosa. Euphytica 124:379-386. doi:10. 1023/a:1015755306547

Joseph SV, Martinez J (2014) Incidence of cabbage maggot (Diptera: Anthomyiidae) infestation and plant damage in seeded Brassica fields in California's central coast. Crop Prot 62:72-78. doi:10.1016/j.cropro.2014.04.016

Joshi RK, Nayak S (2010) Gene pyramiding-A broad spectrum technique for developing durable stress resistance in crops. Biotechnol Mol Biol Rev 5:51-60

Jyoti JL, Shelton AM, Earle ED (2001) Identifying sources and mechanisms of resistance in crucifers for control of cabbage maggot (Diptera: Anthomyiidae). J Econ Entomol 94:942-949

Kergunteuil A, Cortesero AM, Chaminade V, Dourlot S, Paty C, Le Ralec A, Dugravot S (2015) Field and laboratory selection of brassicaceous plants that differentially affect infestation levels by Delia radicum. J Appl Entomol. doi:10.1111/jen.12187

Kirti PB, Prakash S, Chopra VL (1991) Interspecific hybridization between Brassica juncea and B. spinescens through protoplast fusion. Plant Cell Rep 9:639-642. doi:10.1007/bf00231806

Kogan M, Ortman EF (1978) Antixenosis-a new term proposed to define Painter's "nonpreference" modality of resistance. ESA Bull 24:175-176. doi:10.1093/besa/24.2. 175

Kole C (2011) Wild crop relatives: genomic and breeding resources: oilseeds. Springer, Berlin

Lazaro A, Aguinagalde I (1998) Genetic diversity in Brassica oleracea L. (Cruciferae) and wild relatives $(2 n=18)$ using isozymes. Ann Bot 82:821-828

Li L, Zhu Y, Jin S, Zhang X (2014) Pyramiding Bt genes for increasing resistance of cotton to two major lepidopteran pests: Spodoptera litura and Heliothis armigera. Acta Physiol Plant 36:2717-2727

Lucatti AF, Alvarez AE, Machado CR, Gilardon E (2010) Resistance of tomato genotypes to the greenhouse whitefly Trialeurodes vaporariorum (West.) (Hemiptera: Aleyrodidae). Neotropical Entomol 39:792-798

Lucatti AF, van Heusden AW, de Vos RC, Visser RG, Vosman B (2013) Differences in insect resistance between tomato species endemic to the Galapagos Islands. BMC Evol Biol 13:175. doi:10.1186/1471-2148-13-175

Lucatti A, Meijer-Dekens F, Mumm R, Visser R, Vosman B, van Heusden S (2014) Normal adult survival but reduced Bemisia tabaci oviposition rate on tomato lines carrying an introgression from $S$. habrochaites. BMC Genet 15:1-12. doi:10.1186/s12863-014-0142-3

Maharijaya A, Vosman B (2015) Managing the Colorado potato beetle; the need for resistance breeding. Euphytica 204:487-501. doi:10.1007/s10681-015-1467-3

Malchev I, Fletcher R, Kott L (2010) Breeding of rutabaga (Brassica napus var. napobrassica L. Reichenb.) based on biomarker selection for root maggot resistance (Delia radicum L.). Euphytica 175:191-205. doi:10.1007/s10681010-0162-7

McCreight JD (2008) Potential sources of genetic resistance in Lactuca spp. to the Lettuce aphid, Nasanovia ribisnigri (Mosely) (Homoptera: Aphididae). HortScience 43:1355-1358

Muigai SG, Schuster DJ, Snyder JC, Scott JW, Bassett MJ, McAuslane HJ (2002) Mechanisms of resistance in Lycopersicon germplasm to the whitefly Bemisia argentifolii. Phytoparasitica 30:347-360

Muigai SG, Bassett MJ, Schuster DJ, Scott JW (2003) Greenhouse and field screening of wild Lycopersicon germplasm for resistance to the whitefly Bemisia argentifolii. Phytoparasitica $31: 27-38$

Myrand V, Buffet JP, Guertin C (2015) Susceptibility of cabbage maggot larvae (Diptera: Anthomyiidae) to Hypocreales entomopathogenic fungi. J Econ Entomol 108:34-44. doi:10.1093/jee/tou019

Neveu NKN, Nenon JP (1996) A method for rearing Trybliographa rapae W. on Delia radicum L. OILB/SROP Bull 19:173-178

Painter RH (1941) The economic value and biologic significance of insect resistance in plants. J Econ Entomol 14:358-367. doi:10.1093/jee/34.3.358

Painter RH (1951) Insect resistance in crop plants. The MacMillan Company, New York

Pelgrom KTB, Broekgaarden C, Voorrips RE, Bas N, Visser RGF, Vosman B (2015) Host plant resistance towards the cabbage whitefly in Brassica oleracea and its wild relatives. Euphytica 202:297-306. doi:10.1007/s10681-014-1306-y

Pierre SP, Dugravot S, Herve MR, Hassan HM, van Dam NM, Cortesero AM (2013) Belowground induction by Delia radicum or phytohormones affect aboveground herbivore communities on field-grown broccoli. Front Plant Sci 4:305. doi:10.3389/fpls.2013.00305

Prakash S, Takahata Y, Kirti PB, Chopra VL (1999) Cytogenetics. In: Gomez-Campo C (ed) Biology of Brassica coenospecies. Elsevier Science, Amsterdam, pp 59-106

Ramsey AD, Ellis PR (1996) Resistance in wild Brassicas to the cabbage whitefly, Aleyrodes proletella. In: Botos EP (ed) Acta horticulturae. International Society for Horticultural Science (ISHS), Leuven, pp 507-514. doi:10.17660/ ActaHortic.1996.407.64

Rasmann S, Kollner TG, Degenhardt J, Hiltpold I, Toepfer S, Kuhlmann U, Gershenzon J, Turlings TCJ (2005) Recruitment of entomopathogenic nematodes by insectdamaged maize roots. Nature 434:732-737

Schoonhoven LM, Van Loon JJA, Dicke M (2005) Insect-plant biology, 2nd edn. Oxford University Press, New York

Schreiner M, Krumbein A, Knorr D, Smetanska I (2011) Enhanced glucosinolates in root exudates of Brassica rapa ssp. rapa mediated by salicylic acid and methyl jasmonate. J Agric Food Chem 59:1400-1405

Singh R, Ellis PR, Pink DAC, Phelps K (1994) An investigation of the resistance to cabbage aphid in Brassica species. Ann Appl Biol 125:457-465. doi:10.1111/j.1744-7348.1994. tb04983.x

Takeshita M, Kato M, Tokumasu S (1980) Application of ovule culture to the production of intergeneric or interspecific hybrids in Brassica and Raphanus. Jpn J Genet 55:373-387. doi:10.1266/jjg.55.373 
Ten Broeke CJM, Dicke M, van Loon JJA (2013) Feeding behaviour and performance of different populations of the black currant-lettuce aphid, Nasonovia ribisnigri, on resistant and susceptible lettuce. Entomol Exp Appl 148:130-141. doi:10.1111/eea.12084

Van Tol RWHM, Van Der Sommen ATC, Boff MIC, Van Bezooijen J, Sabelis MW, Smits PH (2001) Plants protect their roots by alerting the enemies of grubs. Ecol Lett 4:292-294

Vänninen I, Hokkanen H, Tyni-Juslin J (1999) Attempts to control cabbage root flies Delia radicum L. and Delia floralis (Fall.) (Dipt., Anthomyiidae) with entomopathogenic fungi: laboratory and greenhouse tests. J Appl Entomol 123:107-113. doi:10.1046/j.1439-0418.1999.00315.x

Von Bothmer R, Gustafsson M, Snogerup S (1995) Brassica sect. Brassica (Brassicaceae). Genet Resour Crop Evol 42:165-178
Warwick S I, Francis A, Gugel R K (2009) Guide to wild germplasm of Brassica and allied crops (tribe Brassiceae, Brassicaceae) 3rd edition. Brassica.info http://www. brassica.info/

Wiklund C (1975) The evolutionary relationship between adult oviposition preferences and larval host plant range in Papilio machaon L. Oecologia 18:185-197. doi:10.1007/ bf00345421

Zhu F, Poelman EH, Dicke M (2014) Insect herbivore-associated organisms affect plant responses to herbivory. New Phytol 204:315-321. doi:10.1111/nph.12886

Zohren E (1968) Laboruntersuchungen zu Massenanzucht, Lebensweise, Eiablage und Eiablageverhalten der Kohlfliege, Chortophila brassicae Bouché (Diptera, Anthomyiidae). Zeitschrift für angewandte Entomologie 62:139-188. doi:10.1111/j.1439-0418.1968.tb04118.x 